\title{
VIOLÊNCIA SEXUAL
}

\section{INFANTOJUVENIL: CONTRIBUIÇŌES E RESPONSABILIDADES DOS PROFISSIONAIS DE PSICOLOGIA}

Fábio de Carvalho Mastroianni

Universidade de Araraquara (Uniara)

Tribunal de Justiça do Estado de São Paulo

Ângelo Augusto Rodrigues Alves

Universidade de Araraquara (Uniara)

Anna Beatriz Andriati Fernandes

Universidade de Araraquara (Uniara)

Andreza Marques de Castro Leão

Universidade Estadual Paulista Júlio de Mesquita Filho (Unesp)
Recebido em: 30/01/2020

$1^{\text {a }}$ revisão em: 20/08/2020

Aceito em: 01/10/2020

\section{RESUMO}

Objetivou-se conhecer e analisar a compreensão de psicólogas(os) acerca dos limites, desafios e contribuições da área da Psicologia na atuação com a violência sexual infantojuvenil. Trata-se de pesquisa qualitativa, de caráter exploratório, descritiva e analítica, realizada por meio de entrevistas com nove participantes de três áreas distintas (saúde; assistência social; poder judiciário). Acolher e escutar constituem-se em importantes contribuições da Psicologia, área esta que pode colaborar com o tema de diversas maneiras, sobretudo no que tange a promoção da saúde e do cuidado. Todavia, imersos num cotidiano cuja violência sexual é denunciada corriqueiramente, os profissionais desta área por vezes não dão a devida relevância a prevenção deste fenômeno. Isso desvela a importância de se promover mecanismos voltados a interligar a rede de proteção, indo além da atenção especializada e do poder judiciário, incluindo uma atenção mais acurada à atenção básica e à educação escolar.

Palavras-chave: violência sexual; criança; adolescente; atuação do psicólogo; pesquisa qualitativa. 


\title{
CONTRIBUTIONS AND RESPONSIBILITIES OF PSYCHOLOGISTS TO CHILD SEXUAL VIOLENCE
}

\begin{abstract}
The objective was to know and analyze the understanding of psychologists about the limits, challenges and contributions of Psychology when working with sexual violence against children and adolescents. This is a qualitative, exploratory, descriptive and analytical research carried out through interviews with nine participants from three different areas (health; social assistance; judiciary). Welcoming and listening are important contributions of Psychology, an area that can collaborate with the subject in several ways, especially concerning the promotion of health and care. However, immersed in a scenario where sexual violence is routinely reported, professionals in this area sometimes do not give enough attention to prevent this phenomenon. It reveals the importance of promoting mechanisms to interconnect the protection network, going beyond specialized care and the judiciary, including more accurate attention to primary care and school education.
\end{abstract}

Keywords: sexual violence; child; adolescents; psychologist's performance; qualitative research. 


\section{CONTRIBUCIONES Y RESPONSABILIDADES DE LOS PSICÓLOGOS A LA VIOLENCIA SEXUAL CONTRA NIÑOS Y ADOLESCENTES}

\section{RESUMEN}

El objetivo fue conocer y analizar la comprensión de los psicólogos sobre los límites, desafíos y aportes de esta área en el trabajo con la con violencia sexual contra niños y adolescentes. Investigación cualitativa, exploratoria, descriptiva y analítica, realizada a través de entrevistas a nueve participantes de tres áreas (salud; asistencia social; poder judicial). Acoger y escuchar son aportes importantes de la Psicología, pudiendo colaborar con el tema de diversas formas, especialmente en lo que respecta a la promoción de la salud y el cuidado. Sin embargo, en la rutina donde habitualmente se denuncia la violencia sexual, los profesionales en ocasiones no le dan la debida importancia a la prevención de este fenómeno. Esto revela la importancia de promover mecanismos dirigidos a conectar la red de protección, yendo más allá de la atención especializada y el poder judicial, incluyendo una mayor atención con la atención primaria y la educación escolar.

Palabras clave: violencia sexual; niño; adolescente; desempeño del psicólogo; investigación cualitativa. 


\section{INTRODUÇÃO}

A violência sexual infantojuvenil (VSIJ) é um fenômeno que ocorre em diferentes países independentemente do nível de desenvolvimento e afeta indivíduos de todas as idades e em diferentes contextos segundo os dados da UNICEF (United Nations Children's Fund, 2017). Embora atinja a ambos os gêneros, os dados sugerem que as meninas geralmente correm maior risco, principalmente na adolescência, fase em que a vulnerabilidade delas é mais acentuada. Ainda que grande parte das pessoas imagine que estas práticas sejam realizadas por estranhos ou por meio de estupro, o maior risco de exposição ocorre dentro do contexto de relacionamentos entre familiares, amigos e parceiros íntimos (UNICEF, 2017).

Segundo a Organização Mundial da Saúde (OMS, 2002) a violência é definida como o uso de força física ou poder, podendo se manifestar por meio de ameaça ou na prática, dirigida contra si mesmo, outra pessoa ou grupos, na qual resulta em sofrimento, danos psicológicos, desenvolvimento prejudicado, privação ou até mesmo o óbito da vítima. Já a violência sexual é definida como sendo:

Qualquer ato sexual, tentativa de obter um ato sexual, comentários ou investidas sexuais indesejadas, ou atos direcionados ao tráfico sexual ou, de alguma forma, voltados contra a sexualidade de uma pessoa usando a coação, praticados por qualquer pessoa independentemente de sua relação com a vítima, em qualquer cenário, inclusive em casa e no trabalho, mas não limitado a eles (p. 147).

Diante de um conceito tão amplo, duas manifestações dessa prática podem ser consideradas: a exploração e o abuso sexual. A primeira pressupõe uma relação de mercantilização, na qual o sexo é fruto de uma troca, seja ela de natureza financeira, de favores ou por meio de presentes, podendo ocorrer ou não por intermédio de pessoas ou serviços (Ministério da Justiça, 2014). Já no abuso, as atividades geralmente são praticadas por alguém em estágio de desenvolvimento psicossexual mais avançado, na qual a vítima é usada como objeto para a estimulação sexual (Ministério da Justiça, 2014; Sanderson, 2005).

Pelo uso da confiança ou afeto que o perpetrador utiliza para cometer tal ato, a criança muitas vezes não consegue perceber que está sendo vítima e pode vir a desenvolver a crença de que ela é culpada pelo o que está acontecendo, destarte, por medo da punição geralmente não revela esta situação (Habigzang, Corte, Hatzenberger, Stroeher, \& Koller, 2008). De acordo com o boletim epidemiológico lançado mais recentemente (Ministério da Saúde, 2018), crianças $(74,2 \%)$ e adolescentes (92,4\%) do sexo feminino são as principais vítimas de violência sexual. Além disso, a residência é o local de ocorrência mais apontado $(71,2 \%)$ para as crianças meninas e (58,7\%) para as adolescentes do sexo feminino), e a maior parte 
dos autores destas práticas apresenta vínculo familiar e de amizade ou conhecimento com as vítimas, o que aponta o caráter relacional desses eventos.

Com relação a este aspecto, o citado boletim aponta a dificuldade em dar visibilidade a este problema, seja pelo caráter íntimo e relacional, seja pela menor autonomia dos indivíduos em realizar as comunicações das ocorrências, em virtude, entre outros, do possível receio de estigma social e da vergonha comumente experenciada (Ministério da Saúde, 2018). As razões para a não comunicação podem ser variadas e incluir elementos como: medo de retaliação, culpa, confusão, falta de confiança nas habilidades ou disposição dos outros para ajudar e o desconhecimento dos serviços de apoio disponíveis. Ademais, aspectos socioculturais também podem conduzir a relutância da vítima em se apresentar ou procurar assistência (UNICEF, 2017).

Abranches e Assis (2011) apontam que a atenção sobre a violência praticada contra crianças e adolescentes, sobretudo a violência física, passou a ganhar maior atenção somente a partir dos anos de 1970, quando surgiu o diagnóstico: síndrome da criança espancada. Embora descrita em 1860 pelo médico-legista francês Ambroise Tardieu, o estudo só chamou a atenção da comunidade científica e autoridades um século depois, com a publicação de estudos confirmando essas práticas (Aded, Dalcin, Moraes, \& Cavalcanti, 2006).

No Brasil crianças e adolescentes só passaram a ser consideradas pessoas em desenvolvimento e sujeitos de direitos com a criação do Estatuto da Criança e Adolescente (ECA) lei n. 8.069/1990 (Presidência da República, 1990). A legislação garante o direito à proteção, à vida e à saúde, assegurados por meio de políticas públicas, sendo dever de todos prevenir ameaças ou violações a esses indivíduos. Sempre que os seus direitos forem violados, devem ser aplicadas as medidas protetivas, cujo objetivo é o fortalecimento dos vínculos familiares e comunitários, por isto, em casos de ameaça ou violação, prevê-se o encaminhamento não só destas vítimas, como também dos pais ou responsáveis.

Nas últimas décadas a questão relativa à violência sexual contra crianças e adolescentes vem demandando cada vez mais atenção e cuidados específicos de diversos países. O Brasil, com a aprovação do Plano Nacional de Enfrentamento da Violência Sexual Infanto-juvenil (Ministério da Justiça, 2002) avançou de forma significativa. Este instrumento tornou-se referência e ofereceu uma síntese metodológica para a estruturação de políticas, programas e serviços para o enfrentamento à violência sexual.

Em 2003, iniciou-se um processo de atualização do plano, especialmente para introduzir indicadores de monitoramento e avaliar seu impacto na formulação de políticas públicas nessa área. No processo de revisão do instrumento houve a previsão de se fazer interface direta com as diretrizes do Plano Decenal dos Direitos de Crianças e Adolescentes, sendo ele aprovado pelo Conselho Nacional dos Direitos da Criança e do Adolescente (Conanda) por meio da Resolução n. ${ }^{\circ} 162$ (Presidência da República, 2014). Para o estabelecimento dos indicadores de 
monitoramento, o plano nacional considera diretrizes que estão distribuídas nos seguintes eixos norteadores: prevenção; atenção; defesa e responsabilização; comunicação e mobilização social; participação e protagonismo e, estudos e pesquisas (Ministério da Justiça, 2014).

Quando ocorre a denúncia de violência sexual, crianças, adolescentes e seus familiares devem ser encaminhados para instituições e equipamentos da rede de proteção local. Serviços de saúde como os Centros de Atenção Psicossocial infantil (CAPSi) e equipamentos da assistência social tais como os Centros de Referência Especializado de Assistência Social (CREAS) são instituições que atendem a estas demandas. Além disso, estes casos também são acompanhados pelas equipes técnicas das varas da infância, juventude ou de violência doméstica dos tribunais de justiça.

Essas equipes devem trabalhar de forma articulada e integrada aos demais serviços e equipamentos da rede de proteção, compostas por profissionais de diversas áreas que formam o Sistema de Garantia de Direitos (SGD), entre eles os de Psicologia. Equipamentos da assistência e desenvolvimento social são unidades públicas financiadas pelo SUAS (Sistema Único de Assistência Social) que tem por objetivo oferecer ações de orientação, proteção e acompanhamento psicossocial individualizado e sistemático a crianças, adolescentes e famílias que tiveram seus direitos violados (Silva \& Corgozinho, 2011).

Os centros de saúde são unidades públicas financiadas pelo SUS (Sistema Único de Saúde) e têm por objetivo a atenção em saúde mental focada no cuidado integral. Entre as suas diretrizes, cabe propor ações para atender as demandas em saúde mental de crianças e adolescentes dentro do território de abrangência (Couto, Duarte, \& Delgado, 2008). Assim como ocorre no CREAS, os casos envolvendo denúncia de VSIJ devem ser atendidos de forma prioritária.

Ao poder judiciário cabe acompanhar estes casos, ordenando e articulando os serviços e equipamentos da rede de proteção que possam garantir a aplicação das medidas protetivas às vítimas de violência sexual, bem como a sua família. Para a aplicação das medidas, os juízes geralmente recebem auxílio das equipes técnicas, usualmente formadas por assistentes sociais e psicólogos. A estes profissionais cabe avaliar e analisar a situação, bem como realizar sugestões de encaminhamentos e intervenções necessárias (Ministério da Justiça, 2002, 2014).

Após a notificação da suspeita, o caso deve ser avaliado para que se possa compreender a dinâmica da família e a história da violência sofrida, assim como observar possíveis alterações e demandas que a criança ou adolescente possa estar manifestando. Para isto, é necessário que a criança seja acolhida em um espaço adequado, seguro, no qual receba atenção e se sinta à vontade e confiante para discorrer sobre este assunto (Habigzang et al., 2008).

Tendo em vista a complexidade que este tema exige, torna-se difícil e, ao mesmo tempo, desafiador conduzir a avaliação psicológica de crianças e adolescentes 
envolvendo denúncia de violência sexual (Schaefer, Rossetto, \& Kristensen, 2012). Além do conhecimento técnico, preparo emocional e sensibilidade para lidar com estes casos, o profissional deve se atentar para a articulação entre os diferentes sistemas e instituições envolvidas (Fröner \& Ramires, 2008).

Diante aos impasses que este tema tem gerado na sociedade atual, bem como as expectativas que giram em torno dos profissionais que atendem e avaliam estas demandas, torna-se viável indagar de que modo a Psicologia pode contribuir para estas questões. Entende-se que devido à complexidade, denúncias de VSIJ constituem-se em um grande desafio, sobretudo para profissionais que atuam na área de saúde, assistência e desenvolvimento social, bem como àquelas(es) ligados ao poder judiciário.

Considerando o exposto, o presente estudo tem por objetivo conhecer e analisar a compreensão de psicólogas(os) que atuam em casos envolvendo denúncia de violência sexual contra crianças e adolescentes a respeito dos limites e desafios de suas práticas, bem como das contribuições da área ao enfrentamento deste fenômeno.

\section{MÉTODO}

Trata-se de uma pesquisa de caráter exploratório, descritivo e analítico; as técnicas utilizadas para coleta e análise de dados basearam-se em metodologia qualitativa. A escolha deste método justifica-se por sua capacidade de traduzir e expressar o sentido dos fenômenos do mundo social. Segundo Yin (2016), a pesquisa qualitativa reduz a distância entre o pesquisador e o objeto de estudo, constituindo-se por dados obtidos a partir de um pequeno número de casos sobre um grande número de variáveis discutidas à luz da literatura científica.

Para Flick (2009) o processo de pesquisa qualitativa pode ser representado por dois caminhos, um da teoria ao texto, e o outro, do texto de volta à teoria. A intersecção desses caminhos se dá por meio da coleta de dados e a interpretação destes dentro de um plano de pesquisa. A interpretação, segundo Gomes (2012), assume o foco central na pesquisa qualitativa, uma vez que se busca nos sentidos das falas e das ações, uma compreensão que vai além do descrito e analisado. Para o autor, a interpretação "é o ponto de partida (porque se inicia com as próprias interpretações dos atores) e é o ponto de chegada (porque é a interpretação das interpretações)" (p. 80).

\section{PARTICIPANTES}

Participaram deste estudo profissionais de psicologia lotados em instituições públicas que atendem demandas relacionadas à VSIJ, localizadas em um município do interior do estado de São Paulo. Foram selecionados psicólogos e psicólogas que atuam na área de saúde ou de saúde mental, assistência e desenvolvimento social, além de profissionais ligados ao poder judiciário. A composição da amostra 
levou em conta a experiência com o tema, sendo que o número de participantes foi definido pelo ponto de saturação teórica, ou seja, a amostra se encerrou quando as entrevistas passaram a repetir conteúdos já obtidos anteriormente, tornando-se redundantes (Fontanella, Ricas, \& Turato, 2008; Strauss \& Corbin, 1998). Visando manter o anonimato, os profissionais foram identificados somente em relação à área que atuam: saúde/saúde mental (S); assistência social $(A)$ e, poder judiciário (J), seguidos de um número de identificação: A1; A2 ... J1; J2 ... S1; S2.

\section{CUIDADOS ÉTICOS}

Como se trata de estudo envolvendo seres humanos, a pesquisa foi submetida à aprovação do Comitê de Ética em Pesquisa. Após o parecer favorável n. ${ }^{\circ} 2.685 .770$, foi realizado o contato com os profissionais por intermédio dos gestores da unidade ou com as(os) próprias(os) profissionais. Inicialmente a aproximação e a breve elucidação foram realizadas por telefone; em seguida, de forma presencial, foram mais bem esclarecidas(os) sobre a pesquisa. Ao concordarem, assinaram o Termo de Consentimento Livre e Esclarecido que detalha os possíveis riscos proporcionados por esta pesquisa, seguindo assim, os princípios éticos que visam assegurar aos participantes o sigilo total das informações, de acordo com a Resolução 466/2012 (Ministério da Saúde, 2012).

\section{INSTRUMENTOS}

Foram realizadas entrevistas baseadas em um roteiro semiestruturado, instrumento este criado pelos próprios pesquisadores, após revisão sobre o tema. $O$ roteiro continha perguntas relacionadas à atuação profissional em casos envolvendo denúncias de VSIJ, como por exemplo: "Qual é o seu papel ou função diante da denúncia de violência sexual contra crianças e adolescentes?", "Quais as dificuldades encontradas na realização deste trabalho?", "Quais atividades ou técnicas você utiliza quando se depara com estes casos?", entre outras.

Para as entrevistas, privilegiou-se um local no qual não houvesse ruídos ou circulação de pessoas e que fosse confortável para a(o) entrevistada(o). O registro foi feito com uso de gravador smartphone, para que posteriormente pudesse ser transcrito e analisado. As entrevistas ocorreram entre os meses de março e setembro de 2018, com duração média de aproximadamente uma hora.

Além disso, visando testar a adequação do instrumento (roteiro de entrevista), assim como treinar os entrevistadores, dois discentes do último ano de graduação em Psicologia, foi realizada uma entrevista preliminar com uma psicóloga que já teve experiência profissional com o tema da VSIJ. Por se tratar de uma entrevista piloto e a entrevistada não se enquadrar nos critérios de inclusão, haja vista não estar mais vinculada a estas atividades, os dados desta entrevista não foram utilizados na análise dos resultados. 


\section{PROCEDIMENTOS}

Os dados coletados foram transcritos e a partir do contato com este texto iniciouse a etapa de pré-análise, definida por Franco (2018) como o conjunto de buscas iniciais, de intuições de primeiros contatos com os materiais que tem por objetivo sistematizar os preâmbulos a serem incorporados na elaboração de um plano de análise. Em seguida este material foi submetido à técnica de análise de conteúdo (Bardin, 2016). Esta técnica permite que a palavra seja transformada de forma prática e objetiva em conteúdos inferidos da comunicação e replicáveis ao contexto social (Caregnato \& Mutti, 2006).

Posteriormente, o material coletado foi organizado e categorizado segundo critérios relativamente flexíveis. De acordo com Franco (2018), não existem "fórmulas mágicas", pois em geral: "o pesquisador segue seu próprio caminho baseado em seus conhecimentos e guiado por sua competência, sensibilidade e intuição" (p. 64). Bardin (2016) denomina este processo de categorização, cuja classificação dos elementos é realizada conforme a diferenciação. Em seguida, os dados são reagrupados por temas, de acordo com os conteúdos que vão emergindo da análise, ou seja, as categorias são definidas à posteriori. $\mathrm{Na}$ sequência, foram realizadas as etapas de descrição, análise e interpretação dos dados, possibilitando a compreensão do material (Yin, 2016).

\section{RESULTADOS}

O ponto de saturação teórica foi atingido após a condução de 9 (nove) entrevistas com três participantes de cada área (saúde, poder judiciário e assistência social). Entre estes, seis profissionais são do sexo feminino e apenas um dos entrevistados já atuou em duas áreas distintas, contudo, apesar das contribuições, sua identificação foi atrelada à unidade em que estava ligado no momento da entrevista (saúde).

A análise de conteúdo permitiu encontrar as seguintes categorias: atividade profissional em casos de violência sexual contra crianças e adolescentes; percepção sobre as contribuições do trabalho realizado; repertório técnico para avaliar ou atender estas situações; preparação e formação para conduzir estas atividades e, dificuldades encontradas para realizar o trabalho nesta área. Estas categorias foram agrupadas em três categorias mais amplas e são apresentadas nas subseções a seguir.

\section{FUNČ̃̃ES E CONTRIBUIÇÕES DA PSICOLOGIA FRENTE À VIOLÊNCIA SEXUAL}

O profissional de psicologia pode atuar de diferentes maneiras diante das denúncias de VSIJ, dependendo da área ou instituição em que está inserido. Sua atividade neste campo não se dá de forma isolada, haja vista a abordagem frente ao tema ocorrer por meio de um conjunto de serviços que compõe a rede de 
proteção. No entanto, a análise indicou que em cada área, a(o) psicóloga(o) possui funções específicas.

Nos equipamentos de assistência social, a prática integra-se ao dos profissionais de serviço social. Nesse sentido, volta-se principalmente para o acompanhamento de todo o grupo familiar e não para questões específicas ou individuais: "A gente não faz psicoterapia individual aqui, a gente faz alguns trabalhos em grupo, o trabalho é mais nesse olhar social, tentando mais inserir o sujeito na sociedade do que uma questão mais individual [A3]". Por meio de orientações, acolhimentos e encaminhamentos, busca-se oferecer apoio às crianças, adolescentes e também aos seus familiares: "A gente chama de psicossocial, que não é um atendimento clínico (...) é mais de orientação da família, de apoio (...) nosso papel é de observar, a gente não tem o papel de ficar investigando [A2]".

Destarte, procura-se articular os demais serviços de proteção, visando assim inserilos em atividades de promoção ou outros acompanhamentos necessários:

Quando a gente recebe esses casos, nós fazemos as devidas orientações para as famílias (...) recebemos a família, fazemos os devidos encaminhamentos, aqui nós não fazemos atendimento psicológico (...) a gente acolhe a família, insere as crianças em uma atividade de esporte, oficinas, insere as famílias nos grupos (...) a gente vai tentando articular algumas coisas para que sane qualquer violação de direitos dessa família [A1].

Os profissionais desta área deixam claro que a função deles não é a de investigar, tampouco de realizar atendimento clínico. Já a atividade psicoterápica geralmente é atribuída aos profissionais de saúde que, em suas falas, destacam realizar funções como: ajudar a criança ou adolescente a elaborar: "Acho que de instrumentalizar a criança, ou mesmo o adolescente para lidar com isso, acho que é de ajuda né? [S1]"; bem como de se reestruturar: "(...) que a pessoa consiga se estruturar e se equilibrar para continuar vivendo, então eu acho que a contribuição é essa, da transformação e do aprendizado [S3]", oferecendo-Ihes instrumentos para lidar com o tema da violência sexual:

Tentar reestruturar essa criança, essa família, reelaborar talvez essas situações que ela tenha vivido (...) pra evitar que isso possa se repetir (...) é poder auxiliar (...) a reelaborar essa situação, elaborar essa situação e continuar a vida, continuar dando segmento [S2].

Profissionais ligados ao poder judiciário geralmente atuam quando convocados pelos juízes, visando oferecer considerações e informações sobre estes casos por meio de laudos técnicos. O discurso das participantes indica que a atividade realizada deve se mostrar útil principalmente àqueles que estão envolvidos com o tema da VSIJ: "Eu acho que a nossa questão é sempre focar na proteção da criança e fazer os encaminhamentos que podem estabelecer condições mais favoráveis para ela [J3]". 
As falas sugerem que apesar das atividades serem mais pontuais e limitadas aos objetivos institucionais, sentem que também é possível operar mobilizações e observar as contribuições destas intervenções:

Eu posso te dizer que eu tento me empenhar para que seja efetivo para a criança, adolescente e por tabela para o juiz (...) eu não vou fazer um laudo vago, mas se eu não conseguir dar respostas ao juiz e tiver conseguido ouvir a criança, então eu considero que aquele foi um trabalho importante, eu acho que a lei teve efetividade [J1].

Destarte, a possibilidade de ouvir e oferecer uma escuta que promova reflexão e transformação ultrapassa os objetivos institucionais:

O meu papel é escutar, é tentar compreender (...) levar algumas considerações para os autos do processo na forma de um laudo (...) não é só uma escuta, mas uma escuta transformadora, eu acho que essa é uma qualidade (...) apesar de ser um perito, um avaliador, ser alguém que também está sendo um instrumento de escuta [J2].

No entanto, os profissionais da área de saúde e assistência social, que possuem um tempo de acompanhamento maior junto a estas famílias, entendem que se trata de um trabalho a ser desenvolvido em longo prazo:

Penso que é um trabalho de longo prazo, de formiguinha, de a gente realmente investir nas formas de trazer para os grupos, ensinar (...) nosso trabalho é em transformar, em dar informação, mas é difícil, não é um negócio tão simples assim, é a longo prazo [A2].

Assim, embora observem as contribuições das atividades que conduzem, compreendem que a efetividade também depende do contexto em que é realizada, ou seja, do quanto estas famílias e seus membros são capazes e estão dispostos a permitir uma intervenção, conforme ressalta o profissional da saúde:

(...) todo processo terapêutico ele é um processo, então leva um certo tempo né? O seu sucesso ou o seu fracasso depende das partes envolvidas (...) de como é o suporte familiar que essa criança tem, qual é a própria capacidade que essa criança tem quando a gente pensa em resiliência pra lidar com tudo isso [S2].

E uma psicóloga da área de assistência e desenvolvimento social menciona:

Têm casos muito positivos, tem caso que é efetivo, que a gente consegue fechar, encerrar com um retorno legal, outros não, então assim, vai muito das famílias, têm casos que a gente tem muita dificuldade de fechar o ciclo (...) porquê tem família que 
não permite que a gente acesse a ela, tem família que se fecha [A1].

\section{FORMAÇÃO, PREPARAÇÃO E REPERTÓRIO TÉCNICO}

A maior parte dos profissionais considera que a graduação não ofereceu o respaldo necessário para atuar junto a este tema, conforme se observa na fala de uma psicóloga judiciária: "Nada do que eu tive lá me preparou para aqui [J2]", de uma psicóloga da área social: "Eu tive algum contato durante a graduação, mas nada muito profundo [A3]" e destes dois profissionais que atuam na área da saúde: "Aprendi na minha prática, faculdade não me ensinou [S1]". "Como toda graduação você tem um olhar sobre tudo, sem uma grande especificação [S2]".

Deste modo, indicam a necessidade de se buscar capacitação e conhecimento após a formação: "De vez em quando tem esses cursos online, uma cartilha daqui, uma cartilha de lá, tal, mas assim, sinceramente, eu acho que vai muito da iniciativa de cada um [J1]", haja vista a complexidade deste tema: "A própria complexidade da situação, o que se faz com uma criança que sofreu abuso? [A3]". Neste sentido, indicam que as instituições onde trabalham tentam contribuir: "A prefeitura até chegou a pagar para os profissionais o curso que é específico para abuso e violência sexual, foi muito esclarecedor (...) é a importância, talvez, do profissional se reciclar né? [S1]", mas, segundo uma das profissionais, nem sempre isso é suficiente: "A gente tá tendo pouca capacitação, que é uma coisa que a gente precisa, porque são assuntos delicados, difíceis (...) eu gostaria de ter mais capacitações, a gente precisa de mais capacitações [A2]".

Em relação à atividade propriamente dita, observa-se que diversas são as técnicas utilizadas pelos profissionais: entrevistas individuais, uso de recursos lúdicos e abordagens por meio dos desenhos são citadas pelos participantes tanto da área da saúde, quanto àqueles ligados ao poder judiciário. Os primeiros costumam abordar e trabalhar essa temática por meio de atendimentos individuais e, também em pequenos grupos de crianças ou adolescentes, conforme se observa nestes dois discursos:

Eu parto para uma questão lúdica, com jogos, os desenhos [S1] O que eu trabalho com as crianças são técnicas lúdicas, ludoterapia (...) tenho tanto atendimento individual $e$ as modalidades de agrupamentos, tem dupla, trio, grupinhos de quatro, cinco, seis crianças [S2].

Profissionais que atuam no poder judiciário destacam a importância das técnicas lúdicas e também das avaliações conjuntas com as crianças e suas famílias:

Eu faço entrevistas individuais com os adultos, abordagem lúdica individual com a criança, observação da interação da criança com o familiar (...) a interação é o que traz os melhores elementos para 
análise do caso [J1]. Com a criança é mais com abordagens lúdicas [J3].

Já as duas profissionais da área de assistência e desenvolvimento social indicaram trabalhar em grupos denominados de oficinas, por meio da escuta, do acolhimento e uso de materiais específicos para abordar estas questões: "Nós temos materiais para trabalhar nas oficinas, materiais didáticos, gráficos (...) os grupos, o grupo das famílias [A1]. Ah, a escuta né? O acolhimento, a escuta, observar o comportamento [A2]".

\section{DIFICULDADES E DESAFIOS EM RELAÇÃO À ATIVIDADE COM O TEMA DA VIOLÊNCIA SEXUAL}

Todos participantes reconheceram se deparar com algumas dificuldades em relação ao tema deste estudo, no entanto, dependendo da área de atuação estas dificuldades podem ser mais proeminentes em um discurso do que em outro. Queixas ligadas à maneira como os operadores do direito (juízes, promotores e advogados) lidam com a VSIJ foram apontadas tanto pelas(os) profissionais da área da saúde, quanto àquelas que atuam junto ao poder judiciário, contudo, se mostraram mais acentuadas no discurso destas últimas.

Profissionais da área da saúde entendem que pode ser prejudicial à criança ou adolescente sentirem-se impelidos a abordar o tema da violência sexual, quando há a exigência de um processo e encaminhamento judicial:

Uma intervenção equivocada do poder judiciário, eu vejo que o juiz manda fazer determinadas coisas que (...) não sei se são benéficas, mas que não são eficazes, as vezes mais violentam do que protegem [S1]. É todo o processo judicial (...) o quanto esse mecanismo judicial acaba trazendo um sofrimento aí pra toda família e pra vítima. (...) se o processo não é cuidado, se ele não é feito com zelo, você vai causar de novo um sofrimento à vítima [S2].

Já as participantes do poder judiciário se sentem incomodadas com a expectativa que muitas vezes os operadores do direito possuem em relação às conclusões desses estudos, acreditando ou almejando que seja possível, por meio dos métodos utilizados pela psicologia, se chegar a uma verdade sobre a ocorrência ou não da suposta violência sofrida:

Minha percepção é que ainda tem muito desconhecimento, sobretudo os juízes, promotores sobre o papel da Psicologia (...) eles têm de fato expectativa de que a gente diga se houve [abuso sexual] ou não (...) são ciências humanas, não é matemático [J1]. Vem para nós como se a gente tivesse que descobrir a verdade, quando as coisas são confusas nessa área, nessa questão da verdade absoluta (...) a gente fica nesse território do incerto, em que as nossas palavras têm um peso muito grande [J2]. Acho que 
ainda existe uma fantasia de que nós vamos descobrir uma verdade, assim, absoluta e, nos casos que envolvem a suspeita de abuso sexual, isso é mais forte, eles ficam com essa expectativa [J3].

Embora a questão relativa à investigação da VSIJ se apresentou de forma mais proeminente no discurso das profissionais ligadas ao poder judiciário, participantes das outras áreas também esclareceram os limites e o papel da Psicologia diante destas questões. Profissionais que atuam na área social compreendem que a investigação não é a sua função, pois procuram privilegiar o vínculo e a confiança para poder intervir:

A gente não tem o papel de ficar investigando, "vou fazer um inquérito", esse não é o papel, é o papel da polícia, não é nosso (...) o nosso papel é mais de observar, de estar atento e aí, se necessário, encaminhar [A2]. Essa questão da averiguação, da verificação a gente não entra muito porque a gente precisa do vínculo da família para poder trabalhar [A3].

As mesmas percepções apresentam aqueles que atuam na área de saúde, pois como priorizam o atendimento, compreendem que o foco é com o cuidado e não com a investigação:

Os casos que vem pra cá de abuso ou de um não abuso, eles vão ser olhados e vão ser cuidados (...) quando esses casos chegam pra gente, a gente aqui na área da saúde trabalha a criança [S2]. (...) apesar de não ser, também, o objetivo de dizer se aconteceu ou se não aconteceu, não é da minha competência [S1].

Para profissionais da assistência social a não compreensão acerca das contribuições da Psicologia na área social se estende a outros profissionais: "Tem essa dificuldade, as vezes, de entender o nosso trabalho (...) tanto a saúde, a educação, as vezes até o próprio conselho [tutelar], dependendo da situação, é difícil (...) a gente tem muita dificuldade, as vezes, com a própria rede de serviços [A2]". Além disso, observam a falta de maior integração entre as unidades que compõem a rede de proteção da infância e da juventude:

Se a gente não tem resposta da rede, suporte da rede e dos outros profissionais, o trabalho fica bastante limitado, pois em casos de violência sexual só a escuta não vai resolver (...) a eficácia depende muito do suporte e da estrutura que a rede de serviço dá ao psicólogo [A3].

Com relação à família, profissionais da saúde e da assistência social indicam que um dos principais desafios se relaciona à dificuldade que algumas delas apresentam em iniciar ou prosseguir os atendimentos e encaminhamentos. Alguns admitem a frustração com casos em que, mesmo participando, a família não apresenta a evolução esperada. 
Uma das dificuldades que a gente vê mesmo é a adesão da família às propostas, a família não adere a nenhuma intervenção, nenhuma proposta. Nas visitas, as vezes, a gente encontra condições extremamente precárias, precárias, precárias, as vezes não tem onde sentar, a família não tem onde sentar, a casa está em condições de higiene precária, construção precária, móveis precários, não é fácil, mas a gente tem que estar ali exatamente pra ajudar, a gente tem que [pausa] o mínimo que a gente conseguir já é um avanço pra aquela família, a gente tem que tentar de todas as formas articular a rede pra tentar sanar qualquer dificuldade dessa família [A1].

Uma possível explicação, tanto para os que não aderem, quanto para os que não evoluem, indicada por esta e outros participantes é o contexto de vulnerabilidade em que estas famílias se encontram: "O que a gente percebe em alguns momentos é, muitas vezes, um quadro de vulnerabilidade social, o que torna a intervenção do psicólogo um pouco limitada, por conta dos outros contextos que essa criança está [S2]". Vulnerabilidade que segundo uma psicóloga da área social não se limita apenas às questões econômicas, estende-se e está associada a outras dificuldades e privações: "Você tem a questão financeira, você tem questões familiares complicadas, você tem uso de drogas, você tem problemas de saúde, você tem falta de acesso a lazer e cultura, problemas com educação [A3]".

Já em relação ao funcionamento da família, dois profissionais da área de saúde destacaram as dificuldades existentes nos casos em que os responsáveis desacreditam do discurso apresentado pela criança ou adolescente. Em ambas as falas se destaca a participação da mãe neste aspecto, as quais, mesmo sendo um homem o acusado de ter perpetrado o abuso, assumem postura contra a vítima: "Tem mães que não entendem que a filha não seduziu o pai, não seduziu o padrasto, porque eu já tive casos de a mãe perder as crianças porque ela não se separou do agressor e ainda sente raiva da criança [S3]", atribuindo às filhas a responsabilidade pela ocorrência:

A maioria das vezes, infelizmente, a mãe não acredita, a mãe desconfia. A criança, às vezes, dependendo da intensidade, da frequência, do tempo da exposição do abuso, a criança já vem sexualizada, a própria adolescente já vem sexualizada, então a mãe acha que ela que provocou [S1].

\section{DISCUSSÃO}

A VSIJ exige intervenções interdisciplinares e uma rede integrada de atenção a estes indivíduos e suas famílias, o trabalho realizado pelas(os) participantes deste estudo se mostra importante e também diversificado, o que coaduna com as referências técnicas do conselho de classe dos participantes em relação a esta temática (Conselho Federal de Psicologia, 2020). Entretanto, independente da área de atuação, as atividades desenvolvidas sugerem suscitar duas expectativas 
distintas ao profissional de Psicologia frente ao tema: uma voltada ao acolhimento e à proteção e outra dirigida à investigação. Com relação à primeira, os profissionais se sentem mais à vontade e destacam o acolhimento e a escuta, bem como as orientações e os atendimentos como uma das principais contribuições da ciência psicológica.

Habigzang et al. (2008) em um estudo com meninas vítimas de violência sexual descrevem as vantagens existentes em se relatar a situação sofrida. Para as autoras, o ato de relatar se mostra importante tanto para ativar e reorganizar a memória traumática, quanto para a percepção de que existem pessoas que acreditam em seu relato. Além disso, relatar diante de um profissional auxilia a reestruturar possíveis crenças distorcidas sobre culpa e/ou de se sentir diferente em relação às outras crianças e adolescentes.

Os profissionais da área de saúde, mais voltados para o atendimento clínico, destacaram a relevância não só do acolhimento, como a necessidade em ajudar estas crianças e adolescentes a reelaborar e se reorganizar frente à violência sofrida. Ao mesmo tempo apontaram a importância de se trabalhar os responsáveis que, em alguns casos, desacreditam do discurso infantil, acarretando dificuldades ainda maiores ao tratamento, na medida em que incrementam um sentimento de culpa às vítimas.

Em relação a este tema é válido ressaltar que embora algumas mães possam falhar na proteção das filhas, pesquisas mais recentes também mostram um outro lado desta figura nas situações envolvendo a violência sexual. Segundo Santos, Pelisoli e Dell'Aglio (2012), é necessário destacar as dificuldades e o importante papel protetivo e apoiador destas mães ao enfrentar a situação e realizar a notificação, devendo-se considerar o quanto Ihes é delicado o momento da revelação, haja vista que muitas se sentem confusas, desamparadas, com vergonha e culpadas.

As autoras reforçam ainda a necessidade dos profissionais no auxílio a estas mães, para que o ciclo de violência não se perpetue dentro do sistema familiar. Ademais, não se pode ignorar que a maioria dessas mulheres estão inseridas e muitas vezes repetem a cultura machista ainda em vigência, transmitindo valores nos quais os homens não são responsabilizados pela educação dos filhos e na qual a submissão e dependência em relação ao gênero masculino se perpetua de forma naturalizada (Saffioti, 1987).

Na violência sexual intrafamiliar, ou seja, quando o perpetrador é alguém que pertence ao grupo familiar da vítima, a proximidade da criança ou adolescente em relação a esta figura pode gerar sentimentos conflitantes e angustiantes. Compreende-se que se por um lado a intervenção realizada após a revelação da violência pode the promover proteção e até mesmo alívio, por outro pode the privar o direito à convivência familiar, principalmente quando a denúncia enseja o seu afastamento ou o de alguém de sua família do ambiente doméstico (Cesca, 2004; Santos, Costa, \& Granjeiro, 2009). 
Nestes contextos, não é incomum que as vítimas assumam cada vez mais a responsabilidade pela integridade da família, tendo que ponderar sobre revelar ou não, assim como manter ou não essa revelação. Além disso, a angústia provocada pelos sentimentos ambivalentes por vezes é também intensificada pela inversão da vitimização que alguns praticantes de violência sexual provocam em suas vítimas, levando-as a se sentirem responsáveis pela ocorrência. Ademais, não são raros os casos em que o perpetrador afirma ter sido seduzido pela criança ou adolescente (Zavaschi, Estrella, Jardim, \& Driemeier, 2011).

Já a segunda expectativa (a de que as técnicas e os métodos possam oferecer subsídios para a confirmação ou não da ocorrência) constitui-se em uma das principais dificuldades do trabalho interdisciplinar, principalmente na intersecção com as ciências jurídicas. Além disso, ao assumir uma posição investigativa, a confiança e o vínculo, elementos fundamentais na prática da psicologia, podem ficar prejudicados. Em um estudo qualitativo realizado por Pelisoli e Dell'Aglio (2014a) junto a operadores do Direito, verificou-se que embora eles reconheçam a importância da função protetiva da psicologia, indicam maior interesse na questão relativa à produção de provas, aspecto também apontado por alguns dos profissionais entrevistados nesta pesquisa.

Para alguns autores a ênfase na comprovação da violência sexual leva à sobreposição da punição daquele que a praticou, ao invés de priorizar o tratamento e acompanhamento das vítimas e suas respectivas famílias. Logo, o enfoque acaba sendo muito mais em se comprovar a ocorrência dos fatos e, consequentemente, punir o denunciado, do que em verificar quais são as principais necessidades e demandas da criança, adolescente e de sua família (Conselho Federal de Psicologia, 2020; Gava, Pelisoli, \& Dell'Aglio, 2013; Granjeiro \& Costa, 2008; Pelisoli, Gava, \& Dell'Aglio, 2011). Conforme Pelisoli e Dell'Aglio (2014b) e os participantes deste estudo destacam, são notórios os limites da Psicologia em oferecer respostas a um tema tão complexo.

Outrossim, é importante destacar que a aplicação de medidas protetivas, tais como: encaminhamento e atendimento, entre outras previstas no Estatuto da Criança e do Adolescente (Brasil, 1990), independe da comprovação dos fatos, uma vez que existindo suspeita de violação de direitos ou demanda por parte da criança, adolescente e sua família, estas já se mostram justificadas e devem ser aplicadas (Conselho Federal de Psicologia, 2020). Deste modo, entende-se que a necessidade de comprovação se mostra mais importante ao ordenamento do processo jurídico, do que à proteção desses indivíduos (Yamada, Garcia, \& Uziel, 2015).

Todavia, a relevância que os operadores do direito dão à comprovação da violência sexual e à participação de psicólogas(os) nestes procedimentos passou a ganhar maior relevância com a implementação da estratégia do "Depoimento Sem Dano", atualmente denominado: "Depoimento Especial". As discussões a respeito das contribuições da Psicologia nestes procedimentos exigiram a participação do Sistema Conselhos de Psicologia e, por meio de audiências públicas, o conselho de 
classe da categoria passou a se posicionar no sentido de que aos profissionais cabe o compromisso com a promoção e a defesa dos direitos humanos de crianças e adolescentes (Conselho Federal de Psicologia, 2010, 2019).

Apesar dos esforços e da necessidade de se ampliar e prosseguir as discussões, em 2017 foi sancionada a lei n. ${ }^{\circ}$ 13.431/2017, tornando o depoimento especial estratégia a ser aplicada em todo território nacional (Presidência da República, 2017). Embora mecanismos semelhantes venham sendo aplicados em diversos países, a preocupação apontada pelos participantes deste estudo quanto à expectativa neles depositada de se comprovar a prática da violência sexual parece receber atenção distinta nos estudos internacionais. Publicações recentes ratificam a importância dada ao conhecimento psicológico e a influência destes profissionais em decisões judiciais (Rudas, Valencia, Crissien, García, \& Oliver, 2018), sendo possível observar a ênfase em pesquisar se as características pessoais de psicólogas(os) influenciam na credibilidade das divulgações de VSIJ (Page \& Morrison, 2018).

As participantes que atuam junto ao poder judiciário reconhecem a demanda dos operadores do direito em relação à comprovação da violência sexual por meio dos métodos da psicologia, porém apontaram que nestes casos preferem dar maior atenção às crianças e adolescentes, pois entendem que a escuta e a proteção são atividades mais cogentes, mostrando-se, portanto coerentes com as referências do seu conselho de classe. Cesca (2004) e Yamada, Garcia e Uziel (2015) destacam a importância de os profissionais de psicologia enfocarem estes aspectos, de outro modo, correm o risco de se tornarem agentes e instrumentos de repressão e controle social.

Outro desafio diante destes casos refere-se à formação e capacitação profissional, considerada insuficiente pela maioria. Penso, Costa, Ribeiro, Almeida e Oliveira (2008) apontam a importância de se integrar a teoria com a prática e, em um estudo qualitativo com alunos de psicologia que participaram de atendimentos junto a familiares e vítimas de violência sexual, verificaram que estas atividades podem promover crescimento pessoal e profissional, na medida em que lhes permitem refletir sobre a realidade desta população, bem como a respeito dos preconceitos e discriminações em relação ao tema.

Quanto às capacitações, queixa também apontada pelos participantes, é importante assinalar que elas são previstas e integram o Plano Nacional de Enfrentamento da Violência Sexual (Ministério da Justiça, 2014). No eixo de promoção aos direitos de criança e adolescentes, a qualificação permanente de profissionais constitui-se em uma de suas diretrizes, devendo-se formular e implementar uma política de formação continuada.

O referido plano também destaca a importância de se universalizar o acesso a políticas públicas de qualidade que garantam os direitos humanos de crianças, adolescentes e suas famílias, bem como contemplar a superação das desigualdades por meio da inclusão social. O trabalho a ser desenvolvido na área 
de assistência social foi enfatizado tanto pelos profissionais deste campo, quanto por aqueles ligados à saúde. Participantes destas duas áreas apontaram as vulnerabilidades e os riscos adicionais na dinâmica destas famílias como outro desafio ao trabalho com o tema da VSIJ.

Embora a violência sexual seja um fenômeno universal e presente em todas as classes sociais, as instituições onde os participantes atuam, por serem públicas, geralmente atendem populações economicamente mais carentes. Habigzang, Koller, Azevedo e Machado (2005), em uma análise de processos jurídicos envolvendo abuso sexual infantil, também observaram esta característica na maior parte das famílias. No entanto, mesmo reconhecendo a pobreza e o desemprego como fatores de risco para essa forma de violência, acreditam que situações ocorridas em outras classes sociais nem sempre chegam ao conhecimento do Ministério Público, além disso, famílias mais abastadas têm a possibilidade de procurar serviços particulares.

Ainda em relação ao plano nacional (Ministério da justiça, 2014), observa-se que embora os participantes deste estudo não atuem em unidades ou equipamentos considerados como porta de entrada para problemas relacionados ao tema da VSIJ, nenhum deles descreveu atividades voltadas para o eixo da prevenção como parte de suas funções. Além disso, queixaram-se da falta de integração de atividades voltadas a este tema com os demais serviços que compõem o sistema de garantia e direitos da infância e da juventude.

Cabe observar que grande parte das técnicas e métodos utilizados pelos participantes envolve atividades que visam favorecer a escuta, revelação e a compreensão da situação e da dinâmica familiar, contudo, é importante que os profissionais também direcionem suas ações para a prevenção (Cesca, 2004; Santos \& Costa, 2011). Entende-se que as contribuições da Psicologia para o tema da VSIJ não abrangem apenas a atuação junto ao poder judiciário ou aos centros de atenção especializada, devendo-se ressaltar a importância de se desenvolver este trabalho em conjunto aos profissionais das instituições de atenção básica e da educação (Libório, 2013).

\section{CONSIDERAÇÕES FINAIS}

O presente estudo permitiu conhecer e analisar a compreensão de profissionais de Psicologia a respeito das contribuições, limites e desafios ligados às suas práticas com denúncias de VSIJ. Conclui-se que esta ciência pode colaborar com o tema de diversas maneiras, sendo que o trabalho nesta área requer integração com a rede de serviços e equipamentos, além de uma atuação interdisciplinar. A escuta e o acolhimento nestes casos abrem a possibilidade de se compreender a situação e a dinâmica familiar, constituindo-se numa das principais funções destes profissionais diante do tema. 
Ao oferecer um espaço para relatar e refletir, profissionais de Psicologia podem proporcionar auxílio por meio de orientação e encaminhamentos necessários não somente aos envolvidos, como também aos agentes de outras áreas. No entanto, acolher e ajudar na elaboração do sofrimento não são as únicas contribuições das(os) profissionais da Psicologia que, por meio da promoção e desenvolvimento social, podem auxiliar estes indivíduos e suas famílias para além das questões ligadas à VSIJ, haja vista não ser incomum, principalmente em instituições públicas, se deparar com situações de vulnerabilidade e riscos adicionais.

Imersos em um cotidiano cuja violência sexual já foi denunciada, estas(es) profissionais podem não se atentar para o fato de que a Psicologia também tem muito a contribuir com a prevenção dessas situações. Para isto, é necessário que as atividades voltadas para esta finalidade estejam alinhadas com todos os operadores e unidades que compõem o sistema de garantia de direitos de crianças e adolescentes, conforme instrui o Plano Nacional de Enfrentamento da Violência Sexual (Ministério da Justiça, 2014).

Todavia, a compreensão e a expectativa que muitas vezes se cria em torno da Psicologia quanto à possibilidade de comprovação da violência sexual, indicam tanto os limites da área em oferecer respostas precisas tão almejadas pelos operadores do direito, quanto pode se constituir em um elemento que dificulta o exercício profissional. Independente do campo de atuação, quando diante da VSIJ, psicólogas(os) devem assumir o papel de cuidado e proteção, de outro modo, estas funções poderão ficar comprometidas, caso a expectativa de investigação se sobreponha ao indivíduo e sua família.

Este estudo, entretanto, se limitou apenas aos profissionais que atuam após a denúncia de VSIJ e analisou somente um pequeno número de participantes ligados às instituições que recebem tais demandas, não sendo possível, portanto, estender os resultados a todos profissionais e demais contextos. Pesquisas que envolvam outras realidades e psicólogas(os) que atuam em áreas distintas poderão ajudar a entender melhor as contribuições, os limites e os desafios da Psicologia frente às questões relacionadas à VSIJ.

Em suma, para que profissionais da área da psicologia possam exercer suas funções de forma efetiva e com maior qualidade é necessário se promover mecanismos que favoreçam a interligação entre os diversos operadores que compõem a rede de proteção da infância e da juventude, incluindo tanto a atenção básica, quanto a especializada, poder judiciário e a educação escolar. Além disso, a formação continuada por meio de cursos, pesquisas e uma graduação que privilegie a integração entre teoria e prática de situações envolvendo o tema da violência sexual também se mostra fundamental. 


\section{REFERÊNCIAS}

Abranches, C. D., \& Assis, S. G. (2011, maio). A (in)visibilidade da violência psicológica na infância e adolescência no contexto familiar. Cadernos de Saúde Pública, 27(5), 843-854. https://doi.org/10.1590/S0102-311X2011000500003

Aded, N. L. O., Dalcin, B. L. G. S., Moraes, T. M., \& Cavalcanti, M. T. (2006). Abuso sexual em crianças e adolescentes: Revisão de 100 de literatura. Revista de Psiquiatria Clínica, 33(4), 204-213. https://doi.org/10.1590/S0101-60832006000400006

Bardin, L. (2016). Análise de Conteúdo. Lisboa: Edições 70.

Caregnato, R. C. A., \& Mutti, R. (2006). Pesquisa qualitativa: Análise de discurso versus análise de conteúdo. Texto e Contexto: Enfermagem, 15(4), 679-84. http://dx.doi.org/10.1590/S010407072006000400017

Cesca, T. B. (2004). O papel do psicólogo jurídico na violência intrafamilar: Possíveis articulações. Psicologia \& Sociedade, 16(3), 41-46. https://doi.org/10.1590/S0102-71822004000300006

Conselho Federal de Psicologia (2010). A escuta de crianças e adolescentes envolvidos em situação de violência e a rede de proteção. Brasília, DF: CFP.

Conselho Federal de Psicologia (2019). Discussões sobre depoimento especial no sistema conselhos de psicologia. Brasília, DF: CFP.

Conselho Federal de Psicologia (2020). Referências Técnicas para a atuação de psicólogas(os) na rede de proteção às crianças e adolescentes em situação de violência sexual. (2a ed.). Brasília, DF: CFP.

Couto, M. C. V., Duarte, C. S., \&; Delgado, P. G. G. (2008). A saúde mental infantil na saúde pública brasileira: Situação atual e desafios. Revista Brasileira de Psiquiatria, 30(4), 384-389. https://doi.org/10.1590/S1516-44462008000400015

Flick, U. (2009). Introdução à pesquisa qualitativa. (3a ed.). Porto Alegre, RS: Artmed.

Fontanella, B. J. B., Ricas, J., \& Turato, E. R. (2008, janeiro). Amostragem por saturação em pesquisa qualitativa em saúde: Contribuições teóricas. Caderno de Saúde Pública, 24(1), 17-27. https://doi.org/10.1590/S0102-311X2008000100003

Franco, M. L. P. B. (2018). Análise de conteúdo. (5a ed.). Campinas, SP: Editora Autores Associados.

Froner, J. P., Ramires, V. R. R. (2008). Escuta de crianças vítimas de abuso sexual no âmbito jurídico: Uma revisão crítica da literatura. Paideia, 18(40), 267-278. http://dx.doi.org/10.1590/S0103863X2008000200005

Gava, L. L., Pelisoli, C., \& Dell'Aglio, D. D. (2013). A perícia psicológica em casos de suspeita de abuso sexual infanto-juvenil. Avaliação Psicológica, 12(2), 137-145.

Gomes, R. (2012). Análise qualitativa e interpretação de dados de pesquisa. In M. C. S. Minayo (Ed.), Pesquisa Social: Teoria, método e criatividade (pp. 79-108). Rio de Janeiro, RJ: Vozes.

Granjeiro, I. A. C. L., \& Costa, L. F. (2008). O estudo psicossocial forense como subsídio para a decisão judicial na situação de abuso sexual. Psicologia: Teoria e Pesquisa, 24(2), 161-169. https://doi.org/10.1590/S0102-37722008000200005

Habigzang, L. F., Corte, F. D., Hatzemberger, R., Stroeher, F., \& Koller, S. H. (2008). Avaliação psicológica em casos de abuso sexual na infância e adolescência. Psicologia: Reflexão e Crítica, 21(2), 338-344. https://doi.org/10.1590/S0102-79722008000200021

Habigzang, L. F., Koller, S. H., Azevedo, G. A., \& Machado, P. X. (2005). Abuso sexual infantil e dinâmica familiar: Aspectos observados em processos jurídicos. Psicologia: Teoria e Pesquisa, 21(3), 341-348. https://doi.org/10.1590/S0102-37722005000300011

Libório, R. M. C. (2013). Violência sexual contra crianças e adolescentes: Contribuições da psicologia no processo de prevenção. Psicologia Ensino \& Formação, 4(2), 119-139. Recuperado de http://pepsic.bvsalud.org/pdf/pef/v4n2/v4n2a08.pdf

Ministério da Justiça. (2002). Plano nacional de enfrentamento da violência sexual infanto-juvenil. Brasília, DF: Ministério da Justiça. Secretaria de Estado de Direitos Humanos. Departamento da Criança do Adolescente. Recuperado de http://www.andi.org.br/file/51341/download?token=XCI0_BT8

Ministério da Justiça. (2014). Plano nacional de enfrentamento da violência sexual contra crianças e adolescentes. Brasília, DF: Ministério da Justiça. Secretaria de Estado de Direitos Humanos. Departamento da Criança e do Adolescente.

Ministério da Saúde. Boletim epidemiológico. (2018, junho). Análise epidemiológica da violência sexual contra crianças e adolescentes no Brasil, 2011 a 2017. Brasília, DF. Secretaria de 
Vigilância em Saúde. Recuperado de http://portalarquivos2.saude.gov.br/images Lpdf/2018/junho/25/2018-024.pdf

Ministério da Saúde. Conselho Nacional de Saúde (2012). Resolução $n^{\circ}$ 466, de 12 de dezembro de 2012. Trata de pesquisas em seres humanos e atualiza a resolução 196. Brasília, DF. Recuperado de http://conselho.saude.gov.br/resolucoes/2012/Reso466.pdf

Organização Mundial da Saúde. (2002). Relatório Mundial sobre Violência e Saúde. Recuperado de https://www.opas.org.br/wp-content/uploads/2015/09/relatorio-mundial-violenciasaude.pdf

Page, A., \& Morrison, N. M. V. (2018). The effects of gender, personal trauma history and memory continuity on the believability of child sexual abuse disclosure among psychologists. Child Abuse \& Neglect 80, 01-08. https://doi.org/10.1016/j.chiabu.2018.03.014

Pelisoli, C., \& Dell'Aglio, D. D. (2014a). As contribuições da psicologia para o sistema de justiça em situações de abuso sexual. Psicologia: Ciência e Profissão, 34(4), 916-930. https://doi.org/10.1590/1982-370001032013

Pelisoli, C., \& Dell'Aglio, D. D. (2014b). Psicologia jurídica em situações de abuso sexual: Possibilidades e desafios. Boletim de Psicologia, 63(139), 175-192. Recuperado de http://pepsic.bvsalud.org/pdf/bolpsi/v63n139/v63n139a06.pdf

Pelisoli, C., Gava, L. L., \& Dell’Aglio, D. D. (2011). Psicologia jurídica e tomada de decisão em situações envolvendo abuso sexual infantil. Psico-USF, 16(3), 327-338. https://doi.org/10.1590/S141382712011000300009

Penso, M. A., Costa, L. F., Ribeiro, M. Al., Almeida, T. M. C., \& Oliveira, K. D. (2008). Profissionalização de psicólogos para atuação em casos de abuso sexual. PSICO, 39(8), 211-218. Recuperado de https://revistaseletronicas.pucrs.br/ojs/index.php/revistapsico/article/view/1528/3042

Presidência da República. Casa Civil. Subchefia para Assuntos Jurídicos (2017). Lei $n^{\circ}$ 13.431, de 04 de abril de 2017. Estabelece o sistema de garantia de direitos da criança e do adolescente vítima ou testemunha de violência e altera a Lei n. 8.069, de 13 de julho de 1990 (Estatuto da Criança e do Adolescente). Diário Oficial da União, Brasília, DF. Recuperado de http://www.planalto.gov.br/ccivil_03/_ato2015-2018/2017/lei/l13431.htm

Presidência da República. Casa Civil. Subchefia para Assuntos Jurídicos (1990). Lei $n^{\circ}$ 8069, de 13 de julho de 1990. Dispõe sobre o Estatuto da Criança e do Adolescente e dá outras providências. Diário Oficial da União, Brasília, DF. Recuperado de http://www.planalto.gov.br/ccivil_03/leis//8069.htm

Presidência da República. Secretaria de Direitos Humanos. Conselho Nacional dos Direitos da Criança e do Adolescente (2014). Resolução $n^{\circ} 162$, de 28 de janeiro de 2014. Aprova o Plano Nacional de Enfrentamento da Violência Sexual Contra Crianças de Adolescentes. Diário Oficial da União, Brasília, DF. Recuperado de http://www.lex.com.br/legis_25257036_RESOLUCAO_N_162_DE_28_DE_JANEIRO_DE_2014.a spx

Rudas, M. M., Valencia, S. B., Crissien, T. J., García, I. P., \& Oliver, J. S. P. (2018). Sentencia judicial, delito sexual y pericial psicológica: Enfoque transcultural. Universitas Psychologica, 17(2), 01-11. https://doi.org/10.11144/Javeriana.upsy17-2.sjds

Saffioti, H. I. B. (1987). O poder do macho. São Paulo, SP: Moderna.

Sanderson, C. (2005). Abuso sexual em crianças: Fortalecendo pais e professores para proteger crianças contra abusos sexuais e pedofilia. São Paulo, SP: M. Books do Brasil.

Santos, S. S., Pelisoli, C., \& Dell'Aglio, D. D. (2012). Desvendando segredos: Padrões e dinâmicas familiares no abuso sexual infantil. In L. F. Habigzang, \& S. H. Koller, (Eds.), Violência contra crianças e adolescentes: Teoria, pesquisa e prática (pp. 69-79). Porto Alegre, RS: ArtMed.

Santos, V. A., \& Costa, L. F. (2011). A violência sexual contra crianças e adolescentes: Conhecer a realidade possibilita a ação protetiva. Estudos de Psicologia (Campinas), 28(4), 529-537. http://dx.doi.org/10.1590/S0103-166X2011000400013

Santos, V. A., Costa, L. F., \& Granjeiro, I. A. C. L. (2009). Intervenção no abuso sexual intrafamiliar: Ingerência invasiva ou proteção devida?. PSICO, 40(4), 516-524. Recuperado de https://revistaseletronicas.pucrs.br/ojs/index.php/revistapsico/article/view/4009/4939

Schaefer, L. S., Rossetto, S., \& Kristensen, C. H. (2012). Perícia psicológica no abuso sexual de crianças e adolescentes. Psicologia: Teoria e Pesquisa, 28(2), 227-234. https://doi.org/10.1590/S0102 37722012000200011 
Silva, J. V., \& Corgozinho, J. P. (2011). Atuação do psicólogo, SUAS/CRAS e psicologia social comunitária: Possíveis articulações. Psicologia \& Sociedade, 23(spe), 12-21. https://doi.org/10.1590/S0102-71822011000400003

Strauss, A., \& Corbin, J. (1998). Basics of qualitative research: Techniques and procedures for developing grounded theory (2a ed.). London: Sage Publications Editor.

United Nations Children's Fund. (2017). A Familiar Face: Violence in the lives of children and adolescents. New York, NY: UNICEF. Recuperado de https://www.unicef.org/publications/index_101397.html

Yamada, L. T., Garcia, J., \& Uziel, A. P. (2015). Violência Sexual Contra Crianças e Adolescentes: A Psicologia e o Estado Penal. Psicologia em Estudo, 20(2), 177-188. https://doi.org/10.4025/psicolestud.v20i2.24458

Yin, R. K. (2016). Pesquisa qualitativa do início ao fim. Porto Alegre, RS: Penso.

Zavaschi, M. L. S., Estrella, C., Jardim, F. C., \& Driemeier, F. M. (2011). A avaliação da criança vítima de violência sexual. In M. R. F. Azambuja \& M. H. M. Ferreira (Eds.), Violência sexual contra crianças e adolescentes (pp.136-149). Porto Alegre, RS: Artmed.

\section{AGRADECIMENTOS}

Agradecemos a todos os profissionais de psicologia que aceitaram participar e disponibilizaram seu tempo para a realização desta pesquisa.

\section{CONFLITOS DE INTERESSES}

Não há conflitos de interesses.

\section{SOBRE OS AUTORES}

Fábio de Carvalho Mastroianni é psicólogo formado pela Universidade Presbiteriana Mackenzie, mestre em Ciências da Saúde pela Universidade Federal de São Paulo e doutorando em Educação Escolar pela Universidade Estadual Paulista Júlio de Mesquita Filho (UNESP). Trabalha na linha de sexualidade humana e atua como docente dos cursos de Psicologia e Direito da Universidade de Araraquara (UNIARA). Concomitantemente exerce a função de psicólogo judiciário no Tribunal de Justiça do Estado de São Paulo.

E-mail: psicomastroianni@gmail.com

(2) https://orcid.org/0000-0002-0539-8252

Ângelo Augusto Rodrigues Alves é psicólogo pela Universidade de Araraquara e este estudo é parte de seu trabalho de conclusão de curso para obtenção do título de psicólogo.

E-mail: angeloaralves@hotmail.com

(2) https://orcid.org/0000-0001-9255-4403

Anna Beatriz Andriati Fernandes é psicóloga pela Universidade de Araraquara e este estudo é parte de seu trabalho de conclusão de curso para obtenção do título de psicólogo.

E-mail: annabeatriz.anna@live.com

(3) https://orcid.org/0000-0002-5527-6261

Andreza Marques de Castro Leão é docente do Departamento de Psicologia da Educação, Coordenadora do Programa de Pós-Graduação em Educação Sexual, vice-coordenadora do Programa de Pós-Graduação em Educação Escolar da Faculdade de Ciências e Letras de AraraquaraUniversidade Estadual Paulista Júlio de Mesquita Filho.

E-mail: andreza.leao@unesp.br

(1) https://orcid.org/ 0000-0002-5037-4882 